\title{
Memórias de um Tempo Junto a Crianças com Câncer
}

Memory of a time with cancer children: Reflections about the process of learning to

face disease

Maria do Rosário

Camacho

Universidade

Federal do Espírito

Santo

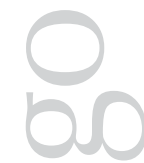

<

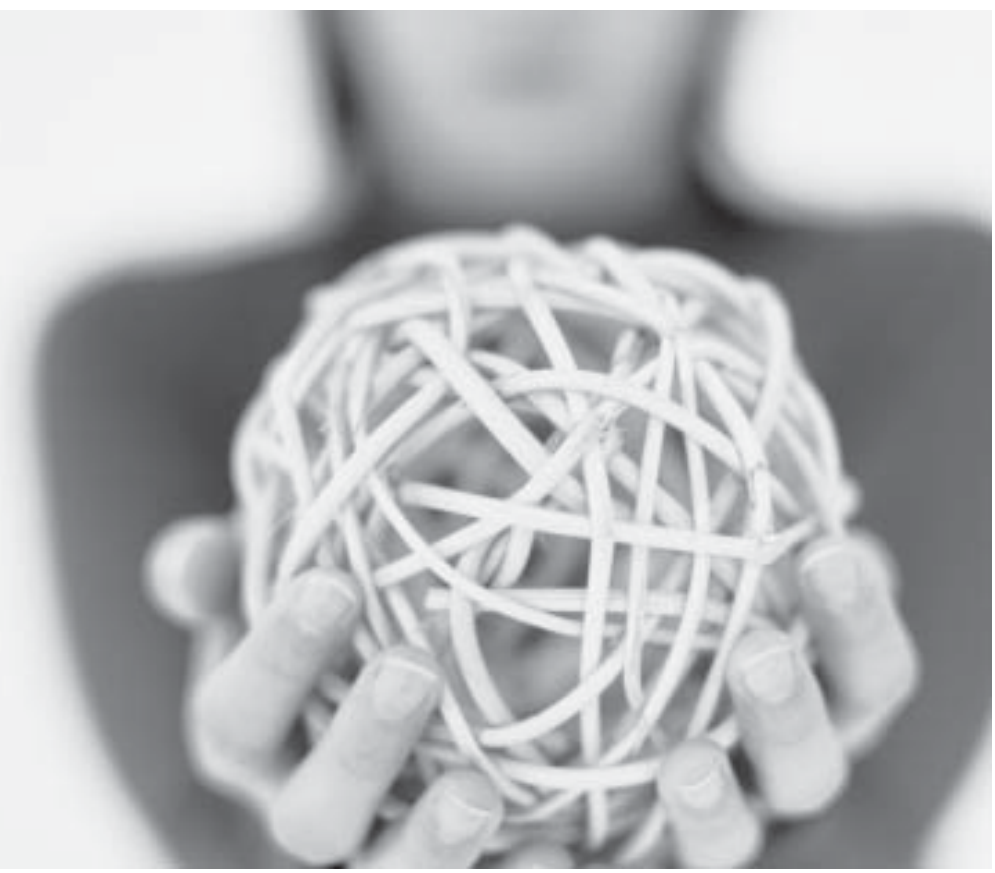

1 Artigo elaborado a partir de dissertação de mestrado em Educação do Programa de PósGraduação em Educação da Universidade Federal do Espirito Santo (UFES) - Orientador: Prof. Dr. Jaime Roy Doxsey. Banca examinadora: Profs. Drs. Hiran Pinel e Antônio Vidal Nunes. Defesa: janeiro de 2003. 


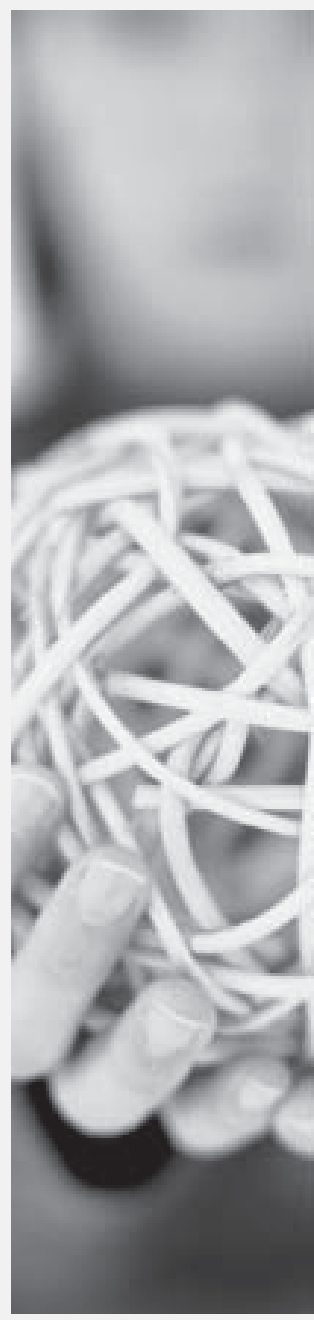

Resumo: Esta pesquisa tem por proposta compreender o processo de aprendizagem construído na rede de interações hospital-doença câncermorte. Trata do processo de aprendizagem frente à doença câncer infantil pesquisando, existencialmente, oitenta e três crianças portadoras dessa doença no Hospital Infantil Nossa Senhora da Glória (HINSG), público e de grande porte, situado em Vitória, Espírito Santo, Brasil. Estuda o conceito de processo de aprendizagem através do método fenomenológico/ existencial (com)vivendo, no Hospital, no período de agosto a dezembro de 2001, com crianças, profissionais e familiares. Utiliza-se de diário de campo, versão de sentido (VS) e procura revelar unidades de sentido, descrevendo as dimensões do processo de aprendizagem efetivado nesse contexto, denominando-as "pólos fronteiriços".

Palavras-chave: aprendizagem hospitalar, ser doente, criação de sentidos.

Abstract: This research aims at understanding the learning process developed by the interaction among hospital-cancer-death. It focuses the learning process of child cancer by observing, through an existential perspective, 83 children who suffer from this disease at the Hospital Infantil Nossa Senhora da Glória (HINSG), a large public institution in Vitória, Espírito Santo, Brazil. The concept of the learning process is studied using the phenomenological/existential method, when close relationships with the hospital staff, the patients and their families were developed, from August to December 2001. The study was conducted through the use of field journal, significance version (SV), which sought to reveal significance units, describing the dimensions of the learning process developed in that context, naming them "frontier poles".

Key words: hospitalar learning, the sick being, creation of meaning.

\section{Hospital-doença câncer: lugares para aprender?}

O hospital infantil é o lugar onde fui na busca de compreender o sentido de ser-criançadoente-com-câncer. Nessa cidade - o sentido - me deixei ficar. Vivi sentimentos fortes que, agora, me pertencem. Aprendi significados ligados ao viver-morrer e, principalmente, ao ser pessoa. Cidade de uma beleza exótica e que muito poucos visitam: é difícil deixar-se estar nesta cidade, envolver-se por ela, ver seu pôr-do-sol e seu amanhecer, os verdes que habitam nas proximidades da morte e suas outras cores, como o vermelho púrpura das bochechas, após uma transfusão de sangue, o branco-"gelo" da ausência de plaquetas e o acinzentado da face daquele que está morto.

Guiada pelo meu desejo de aprender, viajei, então, para uma cidade situada nas fronteiras vida e morte. À fronteira, chamei aprendizagem, e, a essa aprendizagem, denominei Criação de Sentidos.

A inquietação acerca dos fenômenos vida e morte acompanha o homem desde tempos remotos. Para responder a tais inquietações, culturas são constituídas ao longo da História;
"A enfermaria oncológica do HINSG, hoje, está com "algo" acontecendo. Sinto meus passos "leves como os de um gato" [...] vejo alguém partindo desse mundo e nesse encontro é difícil conter as lágrimas [...] Alice, com sete anos, tão "viva" era; tão ruidoso o seu sorriso, suapresença. Penso na solidão da morte cercadapor instrumentos tecnológicos que tenho lido nos I'vros. Nós ficamos aqui, eu e Alice, nossas mãos unidas, numa presença sem palowras"

Diário de Campo 
Sociologiae

Antropologia

realçam aspectos

culturais ao

abordarem

sociedades com

organização

socioeconômica

diversa. Uma

cultura situada

antes do dilívio

bíblico cristão

certamente lidou

com o morrere

com a morte

conforme seu

sistema de

crenças

partilhadas

coletivamente. valores, ritos e crenças guiam atitudes frente a esse desconhecido.

O hospital é um lugar de aprendizagem daqueles que nele se encontram, tendo, por elo, a doença. O Hospital Infantil Nossa Senhora da Glória foi fundado em quinze de agosto de 1935, na região metropolitana de Vitória/ES, numa área de $7500 \mathrm{~m}^{2}$. No ano de 1999, contava com cento e sessenta leitos, oitocentos e trinta e quatro funcionários e um corpo clínico de duzentos e quinze profissionais. A meta do hospital é, nos próximos três anos, estar entre as melhores referências em urgência, emergência e especialidades pediátricas do País.

A instituição hospital tem sua gênese junto à história dos presídios. Conforme relatada na obra de Michel Foucault (1977) "Vigiar e Punir", o hospital nasce como lugar de acolhimento, onde o enfoque é o pobre que está morrendo, e não o doente. É essa a prática vigente até o século XVIII, quando um novo olhar sobre o hospital, como lugar de cura, reorganiza tal instituição. No final do século XVIII, o espaço hospitalar é medicalizado: deverá ser bem localizado para deixar de ser um lugar sombrio onde se vai para morrer. A disciplina dos presídios é "transportada" à instituição hospitalar - regras, horários, arquitetura, distribuição dos leitos. Trata-se da junção das técnicas disciplinar e médica. O poder é transferido do leigo para o médico e, a partir de 1770, o médico passa a residir no hospital. O hospital, como lugar de cura, aparece em torno de 1780, e é marcado pela prática da visita e da observação comparada dos hospitais.

O lugar onde se encontra o Hospital Infantil Nossa Senhora da Glória reflete a força dessa herança. Mães carregam os filhos, ladeira acima, em busca da cura médica. Quando internados, "submetem-se" às regras em geral e, especialmente, à disciplinar. Embora não compreendam "porque um hospital infantil tem que ser construído num lugar assim, com tanto espaço plano em Vitória", a população relaciona-se com o lugar sem deixar de sofrer as marcas da história de sua construção.

É desse ponto, quer dizer, como uma instituição que tem um passado ligado aos presídios e à "caridade", que o hospital se torna personagem da aprendizagem que nele se constrói/(des)constrói.

Falar de aprendizagem dentro da instituição escola e dentro da instituição hospital significa uma tentativa de aproximação do aprender nessas realidades, no entanto, trata-se de um enfoque processual, isto é, dos acontecimentos que habitam tais lugares "geográficos" e que montam a rede (lugar significado) da aprendizagem. A criança hospitalizada é a mesma criança que vai à escola (ou ia); a escola é, para esta criança, um elo fundamental de seu mundo que se rompe. O processo de aprendizagem permanece em movimento, pois não é restrito à escola. Então, a aproximação hospital-escola se dá quando o aprender é visto em processo e a educação como atividade não terminada, após uma aula ou um ciclo pedagógico.

Sociologia e Antropologia realçam aspectos culturais ao abordarem sociedades com organização socioeconômica diversa. Uma cultura situada antes do dilúvio bíblico cristão certamente lidou com o morrer e com a morte conforme seu sistema de crenças partilhadas coletivamente. Assim também a diáspora africana, foco de estudo de Jean Ziegler (1977), possui seus rituais sagrados na organização do fenômeno morte. Então, o modo de respondermos à morte está diretamente ligado à cultura capitalista na qual, historicamente, nos encontramos nos dias atuais.

A Filosofia, enquanto reflexão sobre a condição humana, contribui para a compreensão do significado do existir, mas trata de um homem 
que existe num tempo e sociedade determinados e, portanto, o século XX nos apresenta uma morte coisificada, resultado de um processo histórico-social no qual o Homem se encontra inserido.

\section{O processo de aprendizagem na rede doença-hospital- morte: uma possibilidade de leitura nos referenciais heideggeriano e rogeriano}

O hospital é uma instituição investida de esperança de cura/saúde por aquele que o busca. Tratando-se de, no hospital, permanecer por longos períodos, acaba-se aprendendo e/ ou des-cobrindo a fragilidade dessa função de cura da doença, porém o hospital mantém a mesma posição, e, assim, perpetua a crença de ser um lugar geográfico, socialmente investido do poder de cura biológica mesmo quando todo o seu arsenal técnico falha.

Câncer é sinônimo de estigma no qual se associam rituais purificadores, quer dizer, a crença está no contágio, sendo necessário um distanciamento de todos aqueles que lidam com seu portador. A exclusão é uma prática socialmente aceita, e hospitais apresentam suas raízes fixadas nesse solo: lugar de exclusão/caridade/assepsia. Doença e hospital não se comunicam, apanhadas que estão nessa rede de crenças distorcidas, promotoras de rituais sociopáticos.

Nesse contexto de aprendizagem doençahospital-morte, a morte imprime sua marca determinando um aprender significativo, ou seja, ao encontrar-se com a morte na cena cotidiana do hospital, a consciência do tempo emerge como norteadora de sentido das ações subseqüentes. Testemunhei que essas crianças envolver-se-ão num aprender imediato para garantir sua sobrevivência nesse espaço/tempo e/ou para saber morrer (despedir-se, dividir seus bens, ensinar algo importante).
Posso dizer que as informações oferecidas às crianças e familiares acerca da doença são aprendidas, como também as regras, unilaterais, seguidas no combate à mesma. È quando a morte se apresenta que esse acordo tácito se rompe: a criança capta um novo conhecimento e ultrapassa o saber médico/ institucional. O hospital silencia e segue no seu ritual vazio. A criança aprendeu que morre: o hospital não passou de ano.

A morte que permeia este lugar doençahospital é a morte mesma, quer dizer, a experiência do desaparecimento físico, do findar-se enquanto unidade bio-psico-social. É dessa morte que falam as crianças no cotidiano hospitalar; é essa morte que se esforçam por ocultar aqueles que tratam dessas crianças (profissionais, familiares, outros). É um complexo de relações regidas por forças poderosas não decodificadas, pois falar da morte é grave tabu em nossa sociedade.

A Criação de Sentidos constitui o núcleo do processo de aprendizagem desse ser-criança no espaço-tempo da doença câncer. O que move - dá sentido - a esse aprender é a presença de desejos, escolhas, conflitos e, principalmente, o confronto com a morte. Esse movimento flui na direção do (des)conhecido, ou seja, (des)velando um conhecimento, outro é velado, numa espiral sempre a completar-se.

Mundo vivido não é, simplesmente, um espaço geográfico; trata-se, no dizer heideggeriano, da atividade humana de significar sua ocupação nesse espaço. Esse mundo vivido caracterizase por ser circundante, próprio e humano, dando, ao espaço ocupado, uma significação que passa pela singularidade de cada um. Esse mundo vivido é também compartilhado com outros, pois somos ser-em-relação. Então, a existência acontece dentro de um mundo vivido e, portanto, espacializado numa extensão temporal. O tempo é experimentado como o que pertence ao ser e o que lhe será tirado diante da morte.
Câncer é sinônimo de estigma no qual se associam rituais purificadores, quer dizer, a crença está no contágio, sendo necessário um distanciamento de todos aqueles que lidam com seu portador. 
No mundo vivido da doença-hospital-morte, esse ser criança se angustia - é por torná-lo mundo vivido que surge tal angústia - no entanto, só assim poderá sobre-viver na espera; é a angústia, abertura privilegiada do ser, que des-vela o ser-para-a-morte. Compreendendo que morre ou que está em confronto com a morte, o ser-criança dá sentido a esse lugar vivido e ao existir nesse lugar. É bom ressaltar que, para a maioria dos habitantes do contexto hospital-doença-morte, esse mundo permanece não vivido. A compreensão, experimentada pelo ser de compreensão, em totalidade, como ser-paraa-morte, é a cura. Curar-se, nesse espaçotempo doente-com-câncer, é existir com sentido, envolvendo-se em projetos que priorizem escolhas autênticas.

Aceitação incondicional e compreensão empática são condições para o fluir do processo das aprendizagens significativas. Rogers (1982) as coloca como experiências que precedem mudanças em crenças, valores e atitudes, sendo, portanto, mediadoras da Criação de Sentidos.

O contexto hospital-doença-morte apresenta entrelaçamentos não aceitos e não compreendidos que vêm à tona nos acontecimentos do cotidiano hospitalar, um ciclo vida-morte que se alterna, forçando o contato com essa realidade não compreendida.

O saber-se em confronto com a morte funciona como elo mediador na atividade de criação de sentidos, pois imprime imediatismo às escolhas, congruência às comunicações e aceitação do ser doente/finito. Essa aceitação do processo pelo ser-criança o torna diferente junto ao grupo - ele parece saber algo que os outros não sabem - abrindo-se à experiência do adoecer. No entanto, trata-se de uma parcela dessa população, ou seja, a aceitação ocorre num pequeno grupo e/ou num nível individual.
O aumento no grau de abertura à experiência e no grau de congruência nas comunicações são índices de um processo de mudança em andamento, descritos por Rogers (1982). Tais mudanças se refletirão no grupo que habita o espaço doença-hospital-morte como base de crenças que nortearão novas práticas, receita difícil no contexto onde a crença na técnica que direciona a prática vigente reduz drasticamente a abertura ao experienciar, bem como o grau de congruência nas relações. $\mathrm{O}$ nível de aceitação desse tempo/doente flutua conforme o nível de aceitação nas relações, então o ser-criança apresentará uma nãoaceitação desse estado de ausência de saúde, ficando aprisionado nas significações já existentes (câncer-morte-desesperança). Esses dois grupos convivem no cotidiano hospitalar - um grupo que aceita e expressa congruência e um outro que não consegue aprender. $\mathrm{O}$ ser-criança fala em gestos, silêncios, palavras, olhares, e comunica-se com o ambiente, com seus colegas, com seus familiares, consigo próprio, demonstrando que busca deixar aberto ou abrir o processo de aprendizagem.

A dimensão cognitiva encontra-se na rede de nossas vivências, no entanto, o ser que aprende não se reduz às suas dimensões. $\mathrm{O}$ cognitivo estará submetido às nossas vivências, traduzidas num contínuo sempre mutável do seu próprio experienciar. O contínuo fluido se realiza num movimento onde uma abertura experiencial, com relação ao mundo e a si mesmo, aumenta seu grau à medida que experiências recebem significado no campo perceptivo/fenomenal - busca-se um nome, uma palavra ou um conceito que possa traduzir o experimentado de forma cada vez mais precisa para aquele que experimenta, trabalho construído no entrelaçamento cognitivo/afetivo na rede de aprendizagem denominada Criação de Sentidos.

Situar o processo de aprendizagem denominado Criação de Sentidos nos referenciais heideggeriano e rogeriano é 
chamar a atenção para a primazia do ser que aprende. Trata-se de um enfoque que passa pela perspectiva existencial da abordagem humanista permitindo um diálogo entre esses dois autores sem, no entanto, reduzi-los à leitura aqui empreendida.

\section{Criança: um jeito de ser-no-mundo}

Crianças morrem. Crianças enfrentam a dor, o sofrimento e morrem ou (sobre) vivem. A morte faz parte da vida, e o encontro do homem com sua finitude é carregado de angústia. Essa morte chega de forma diferente para cada um conforme a classe socioeconômica a que se pertence. Como é ser-criança-doente-com-câncer num hospital público?

O historiador P. Ariés (1981) aborda a construção do conceito de infância. Com base nesse autor, é possível refletir a relação adultocriança vigente em nossa sociedade contemporânea: as características de infantilização e dependência que o adulto imputa à criança determinam uma relação baseada no autoritarismo-submissão que retira da criança seu direito de ser - livre, criativa, espontânea. Essa história naturalizou um conceito de criança permeado por elementos "estranhos" ao seu mundo. Uma abordagem da criança como jeito-de-ser pretende liberar a riqueza presente nesse ser-criança, não como caracteres biológicos específicos ou fases de desenvolvimento pelas quais se passa, ou, ainda, alguém que não é adulto. O que desejo é abordar a criança a partir do referencial da própria criança, tomando-a em seu olhar (sercriança) e não olhar sobre ela - um ser inteiro, não seccionado.

\section{Eu brinco com palavras}

Como ontem brinquei com

Cacos de porcelana quebrada.

Meus banquetes, estou te servindo
Como dei de comer às minhas bonecas;

Brinco de ser gente!

Brinco construindo mundos

Para você habitar.

Brinco de inventar!

Vem brincar?!

O tempo de criança está guardado em mim como memórias. Não se trata de rememorar acontecimentos, mas o jeito de ser criança. Sei como fui na minha infância - curiosa com os mistérios da vida, observadora da natureza, reflexiva com relação aos acontecimentos, esperta em captar as mensagens dos adultos à minha volta e capaz de seguir pistas que esses adultos me davam para comportamentos e ações, amante da quietude que se fazia naquele lugar onde vivia. Na quietude, ficava arrumando teorias sobre a vida e, às vezes, essas teorias pareciam emergir do fundo, de um lugar desconhecido, carregadas de sentimentos fortes. Uma espécie de plenitude reinava, e eu me sentia pertencente a um mundo maravilhoso; sentia-me grata à vida e a seus mistérios, estar na quietude, no esconderijo de sua/minha/nossa casa, pois, como dito nas palavras de Benjamin (2002), a criança conhece todos os esconderijos da casa e retorna a eles como a um lar onde se está seguro de encontrar tudo como antes [...].

Esse jeito-de-ser está em mim hoje, e apresenta-se, em especial, quando me relaciono com crianças. Parece que é esse espaço que sintoniza nossa cumplicidade nas atividades do cotidiano do contexto doença-hospital-morte.

O tempo é vivenciado no contexto doençahospital-morte. Dentro de um hospital, longe das rotinas, frágeis elos que nos dão o senso de realidade, torna-se difícil "segurar" referenciais de tempo - será dia ou noite? Estou aqui faz dias, semanas, meses? Fazendo aniversário aqui, terá decorrido um ano inteiro? O tempo, aqui na enfermaria oncológica infantil, é o das estações, aquele que se move em dia e noite.
O tempo de

criança está guardado em mim como memórias. Não se trata de rememorar acontecimentos, mas o jeito de ser criança. Sei como fui na minha infância - curiosa com os mistérios da vida, observadora da natureza, reflexiva com relação aos acontecimentos, esperta em captar as mensagens dos adultos à minha volta e capaz de seguir pistas que esses adultos me davam para comportamentos e ações, amante da quietude que se fazia naquele lugar onde vivia.
2 Foi buscando a criança em mim que fiz essa "quase" poesia. A linguagem poética me ajudou a deixar fluir um conhecimento através da linha do tempo. Lembreime de minhas brincadeiras com cacos de porcelana e pude, assim, aproximar-me do desejo da criança hospitalizada ao me pedir retalhos de tecidos para confeccionar roupas de bonecas. 
A infância, vista como um processo, traz a possibilidade de uma leitura do ser-criança como totalidade e, em conseqüência, participa da construção de subsídios para um novo olhar sobre o aprendizado que se realiza nesse tempo/espaço doente-com-câncer. Significa dar voz à criança, respeitando-a em sua singularidade.

Na tríade doença, hospital, morte, a criança encontra-se diante de um aprender singular. Vivendo esse espaço-tempo, desejará tornálo representativo de sua real (sobre) vivência. O processo de aprendizagem que aqui se desenrola será, então, a Criação de Sentido para cada ação realizada ou acontecimento vivido. O enfoque num aprender significativo como aquele que se reflete na conservação e enriquecimento do organismo é apresentado por Carl Rogers (1982) em sua obra "Tornarse Pessoa". O referencial rogeriano é a trilha que escolho para pensar o aprender no contexto hospital-câncer-infantil. A criança aprende como possibilidade vital de continuar sua construção: vir-a-ser permanente no espaço-tempo da doença câncer infantil.

Criança é um jeito-de-ser-no-mundo que permanece na fluidez do tempo. Esse enfoque é o que permite compreender esse sujeito que aprende dentro de um hospital, face à doença e morte. Esse tempo não é uma fase chamada infância ou tempo com câncer, mas sim, a vivência de um presente que engloba passado e futuro: é um presente distendido no imediato.

Esta pesquisa tem por proposta compreender o processo de aprendizagem construído na rede de interações hospital-doença câncermorte. Trata-se de um estudo exploratório inspirado na abordagem centrada na pessoa (ACP) e que, no processo de sua construção, utiliza-se do método fenomenológicoexistencial.

O que se busca comunicar é o vivido junto às crianças-com-câncer; para tanto, utiliza uma linguagem que prioriza preservar esse vivido: poesias, fotografias e uma narrativa na primeira pessoa do singular. Assim, o que se segue representa uma das muitas possibilidades de uma versão de sentido para a experiência vivida. Há momentos em que fico sem palavras diante desses encontros, então emerge uma linguagem poética que optei por incluir. Selecionei, também, algumas das fotografias que tirei dos ambientes: são imagens que buscam comunicar, por uma outra via, o vivido.

\section{Percurso metodológico}

O percurso metodológico foi construindo-se à medida que minha convivência aumentava e apertava laços e mais laços. Não há uma preocupação explícita em demarcar as etapas clássicas da metodologia científica, uma vez que, ao narrar, uma ordem se apresenta.

Meu desejo de entender o aprendizado construído no enfrentamento da doença câncer infantil apresentou-se como inquietação: Quais as dimensões desse processo? Será possível identificá-las e descrevê-las considerando o olhar da criança com câncer? Tendo por referência o meu conviver junto às crianças, seria possível captar o sentido atribuído por essa criança à aprendizagem que se dá nesse contexto? O desejo foi assim enunciado: compreender o processo de aprendizagem frente à doença câncer infantil, em especial, a contribuição da doença e o confronto com a morte nessas aprendizagens.

Estar com essas crianças desencadeou, em mim, fortes sentimentos. Esse envolvimento, presente no meu percurso de pesquisadora, norteou a busca de respostas às indagações propostas. Tal postura rompe o paradigma sujeito/objeto, que preconiza a neutralidade do pesquisador frente ao fenômeno pesquisado.O trajeto que percorro é o da metodologia fenomenológica-existencial, pois, com base nessa proposta, não posso falar em 
neutralidade, ao contrário, o que ressalto é o envolvimento na Criação de Sentidos.

Escolhi intencionalmente o Hospital Infantil Nossa Senhora da Glória (HINSG), e, no período de agosto a dezembro de 2001, estive envolvida nesse ambiente, nas situações que se apresentaram no cotidiano hospitalar. Delimitei um tempo cronológico de dez horas semanais, que foram cumpridas em espaços variados, compreendendo as manhãs, em seu início e findar, as tardes, em seu início e findar, e o anoitecer. Propus-me escutar a criança onde quer que a encontrasse: nas dependências do ambulatório de oncologia, na enfermaria, na classe hospitalar $(\mathrm{CH})$, sentada no pátio, caminhando pelos corredores, subindo a ladeira do hospital, em situações de procedimentos médicos, aguardando consultas e exames, em atividade lúdicas, no pós-cirúrgico, recebendo alta hospitalar ou nas primeiras informações sobre a doença. Duas outras situações que se apresentaram foram as reuniões de mães-paisresponsáveis, ocorridas na sala da psicóloga, e as comemorações do Dia da Criança (12/10) e do Natal (25/12), que ocorreram num ambiente fora do hospital (casa de festas). No meu estar pesquisadora, laços foram criados com oitenta e três crianças entre zero e dezessete anos, trinta e nove familiares, dezesseis profissionais e seis voluntários da ACACCl, totalizando uma população de cento e quarenta e quatro pessoas envolvidas na pesquisa.

Nenhum material didático foi previamente elaborado para provocar situações, todavia, quando a escuta apontava desejos, eu os ouvia. Nessa direção, ofereci papel ofício, lápis de cor e hidrocor para desenhos livres, máquina fotográfica, fotos do meu aniversário e família, tecido, linha, tesoura e agulha para confeccionar roupas de boneca e um caderno de desenho coletivo.

Escutando, apreendi o conteúdo escutado em mim, em seguida, registrei-o no diário de campo. Os registros do diário são a transcrição do que gravei na minha memória em cada encontro realizado. Nesse registrar, via-me refazendo o percurso, num retornar à cena para descrevê-la, fenomenologicamente: meus sentimentos ao chegar, os atos rotineiros, como sentar e observar no ambulatório ou colocar o jaleco e lavar as mãos na enfermaria, o movimentar das pessoas pelo ambiente, os cheiros, os sons, os olhares, os toques, as lágrimas, os sorrisos, as falas, os silêncios, as cenas que me tocaram e seu contexto, meus sentimentos ao partir. Estive aberta a escutar o dito e o não dito, esforçando-me para suspender preconceitos e julgamentos prévios, o que implicou um ouvir a mim mesma na situação, registrando e refletindo sentimentos e inquietações frente ao que foi ouvido. Tratase de uma postura existencial que se fundamenta nos princípios da abordagem centrada na pessoa (ACP). Os registros do diário de campo foram realizados como narrativas onde o encontro pode ser percebido como cena, e a leitura das cenas, por sua vez, podem remeter ao acontecimento que descrevem. Para narrar, o narrador experiencia o narrado, mergulhando-o em si, e o transmite ao ouvinte/leitor, que o apreende, tornandoo parte de si.

Na etapa seguinte ao percurso metodológico, dispus-me a ler e reler as narrativas do diário de campo, relacionando-me com o lido, tendo por guia a questão norteadora da pesquisa: a Criação de Sentidos nessa aprendizagem peculiar. À medida que me dediquei à leitura, destacaram-se elos nas vivências registradas, e então escolhi, no universo do diário de campo, quatorze personagens que, no decorrer das narrativas, revelaram-se significativos à compreensão da questão proposta. A cada transcrição, o sentido tornavase mais claro, e, assim, emergiu, de mim, uma nomeação das narrativas como imagens sintetizadas num título, num nome que preserva sua ligação com o vivido dando-lhe significado no contexto descrito. 
Essas quatorze narrativas foram alvos de conversas, isto é, como pesquisadora, (con) versei com elas extraindo-lhe dimensões do processo de aprendizagem significativa permeado pela morte, liberando seu sentido. Foram quatro dimensões identificadas como unidades de sentido que aqui se fizeram: informação-experiência, identidadedeformação, negação-aceitação, projetosmorte. Chamei pólos fronteiriços e entre-pólos o lugar onde ocorre a Criação de Sentidos.

Essas são as narrativas e sua nomeação (em negrito), que se apresentaram como cena do processo de Criação de Sentidos: Olhando, juntos, a morte pelo corredor, velando o suspirar de Alice enquanto a morte se faz, encantar-se com as vitórias da bela Victória; curvar-se ante a luta de Caio para ser (Eu sou Caio, o lutador), mesmo em coma; receber o carinho de José em despedida (com carinho, José); testemunhar o sonho de vir-a-ser (o) violeiro; participar da guerra junto a João, o general otimista; ser tocado pela leveza de Maria; ver o azul do céu refletido nos olhos de João (olhando o azul do céu); entrar no silêncio e profundidade de olhos negros como jabuticabas; envolver-se com as gentilezas de um príncipe chamado José; sofrer, resignadamente, por amor de Ruth; aprender a sorrir do destino com João, o "humorista"; pedir a Érica, nos momentos de cansaço e desistência: me nina, menina!

\section{Reflexões finais}

A reflexão sobre o Homem, a partir da Filosofia e das ciências sociais, torna-se fundamental para a compreensão da dinâmica complexa que se estabelece no interior da instituição hospital. O homem que habita esse contexto partilha crenças e valores que constroem formas de percepção do morrer e determinam práticas cotidianas que se cristalizam no tempo. Sociologia e Antropologia realçam aspectos culturais ao abordarem sociedades com organização socioeconômica diversa. O modo de respondermos à morte está diretamente ligado à cultura capitalista na qual, historicamente, nos encontramos nos dias atuais.

No final de um dos corredores de um hospital público, está o ser-criança-com-câncer. Houve momentos em que pensei que não encontraria autores que pudessem dialogar sobre esse lugar vivido (que eu estava vivendo). Não haviam, ainda, inventado as palavras. Eu também ainda não havia aprendido que a língua aqui é outra, como diz Heidegger, nada de falatório. Nesse contexto, a criança envolvese com o processo da aprendizagem significativa na busca de Criação de Sentidos. Estar nessa rede de aprendizagem é expor-se a movimentos constantes desse processo singular: a aprendizagem significativa na ação de Criar Sentidos.

Processo é um conceito que se liga a movimentos, e esses movimentos se fazem num contínuo, como afirma Rogers (1982), em direção à fluidez, tendo por meta a abertura à experiência - tornar-se pessoa. Processos se fazem nas relações, ou seja, como apreensão de significados vividos de encontro a encontro, mas que pertencem ao encontro, e não aos participantes em separado, no dizer de Amatuzzi (2001).

O processo de Criação de Sentidos apresentouse como pólos de um contínuo fluido. A aprendizagem se realiza nos entre-pólos à medida que o sentido é liberado. A seguir, uma descrição dos pólos identificados:

Informação-experiência: a informação está presente no cotidiano; trata-se de comunicar um acontecimento, como: quem morreu, as regras do hospital, o exame que vai fazer, etc. Saber tais conteúdos é dominar o dialeto hospitalar e ter a sensação de segurança para mover-se nesse espaço. Sugere, também, que se pode controlar o adoecer. $\mathrm{O}$ alívio que traz 
a informação se reflete no aumento da capacidade de suportar o sofrimento, no entanto, há uma tensão constante entre informação e experiência, o que leva à queda do poder da informação e força o experienciar da dor/desamparo.

Identidade-deformação: identidade é um processo construído nas relações, com ênfase para as que são significativas, isto é, que possuem a aceitação incondicional do ser em construção, tarefa difícil quando o ser em questão é o ser-criança-doente-com-câncer. Percebo esse pólo como danoso, impedindo o processo de fazer-se e/ou impondo uma direção deformada à construção, o que traz depressão e baixa auto-estima como conseqüência. Percebi as crianças tentando preservar o "eu" num senso de sobre-vivência "forte" (deforma-se para sobre-viver).

Negação-aceitação: sofrimento físico e emocional; desencadeia a defesa da negação nos habitantes e frequentadores desse lugar. A experiência da aceitação é condição básica para o mover-se nesse pólo. O aceitar se faz no contexto relacional, ou seja, aceitar-se doente-com-câncer e ser aceito como doentecom-câncer, movimento difícil junto à dor e factualidade da vida (morte), especialmente para os que vivem esse tempo.

Projetos-morte: A liberdade de escolha impulsiona projetos. O ser é livre para escolher em sua existência, e, diante da ameaça de morte e sofrimento prolongado, escolhas são exercidas com imediatismo e coragem. Escolher dois pães com ovos para o lanche, escolher não raspar a cabeça e deixar seus cabelos caírem são indicações do processo acontecendo. Exercitando as habilidades de escolher, constroem-se projetos: ser médica, ser violeiro e cantor, ir para o pré-escolar e viver para realizar os projetos escolhidos. No hospital, na evolução do adoecer, experimenta-se a imobilização que acarreta dependência do outro nas relações, deslocando o centro das escolhas para o exterior e enfraquecendo essa habilidade.

Identifico os pólos descritos junto ao grupo das crianças; no entanto, toda a população hospitalar - profissionais, crianças, mães, outros - participam dessa complexa rede de aprendizagem envolvida na Criação de Sentidos.

\section{As dimensões educativas: brincar, conviver, sensibilizar-se}

Aponto dimensões educativas que se apresentam no enfrentamento da doença câncer infantil, porém ressalto que educar, nesse contexto, significa soltar-se à incerteza: não se identifica um currículo, um método pedagógico a seguir, um critério de avaliação a ser adotado, nem mesmo estratégias certeiras para um aprender garantido.

Atitudes são educativas quando congruentes com as crenças que carregam. Atitudes são mais importantes que técnicas na viabilização da criação de sentidos. Concretiza-se no gesto: abraçar, tocar, sorrir, limpar a saliva que escorre, pegar no colo, segurar a mão, caminhar ao lado, emocionar-se, trocar quando solicitado, etc.

Conforme o extrato do Diário de Campo, abaixo citado, no contexto hospitalar, as atitudes permanecem no conteúdo informativo. A incongruência nas atitudes será a tônica com o evoluir do adoecimento, pois os gestos estarão contaminados pelo escamotear de informações e, por isso, passam a rarear ou a serem recusados.

Érica me chama para contar as novidades. Fará RX do tórax para descobrir de onde vem a febre. Victória me diz que suas plaquetas estão baixas. João me ensina que a "bombinha" 
conta o remédio gota-a-gota e, por isso, ficará 24 horas sem sair de sua cama. Bruno me informa que colocou cateter na veia embaixo do braço, e o procedimento é para evitar muitas furadas. Pelo cateter, pode-se tomar medicamentos e até colher sangue para exames. Esclarece-me que não dói, porque nessa área tem pouca "carne". Ricardo enrola a língua para dizer mielograma, mucosite, punção lombar, biópsia. Nomes estranhos que agora estão incorporados ao dialeto cotidiano (extratos do diário de campo).

Conviver é compartilhar espaços, tempos, experiências, valores. A convivência educa quando compartilha as crenças que permeiam as práticas cotidianas. Profissionais, familiares e recreadores compõem grupos distintos em relação ao grupo das crianças, e cada grupo é orientado por crenças que o levam a se empenhar em tarefas e/ou papéis sociais que, acreditam, lhes é atribuído.

Os familiares atuam como educadores, fortalecendo as crenças dos profissionais na eficácia da técnica. Na evolução do adoecer, familiares e profissionais perdem seus métodos, conteúdos e objetivos educativos.

O grupo das crianças é o principal educador da convivência, pois partilham coletivamente, e de forma congruente, suas crenças/ descrenças. Na evolução do adoecer, permanece educando a partir da renovação de métodos, conteúdos e objetivos, tendo por base a incerteza como elemento fundamental de seu currículo.

Momentos como o que se relata a seguir irrompem no cotidiano, construindo, rapidamente, uma nova rede de aprendizagem. As crianças respondem ao convite de "jogar o jogo" conforme desejos e necessidades próprios; nesse espaço, o que se tem em comum é partilhado na direção das "cartadas".

Estamos jogando cartas: eu, Érica, João e José (o príncipe). É o jogo com trunfos, e Érica está ganhando. José faz uma jogada, muda o trunfo, junta as cartas e diz que ganhou. Fico surpresa; João dá gargalhadas e Érica se aborrece, saindo da brincadeira. João pergunta a todos na enfermaria: "vocês sabem jogar cartas?" Pega uma das cartas e a lança na direção de Ricardo, que está "preso" à cama; este joga-a de volta para João. Num instante estamos todos, na enfermaria, jogando cartas uns para os outros. Rimos pra valer! (extrato do diário de campo).

A atividade do brincar é, por si só, educativa. Destaco, nesse contexto, os jogos, as histórias infantis e o desenho livre. Brincando, arrumamse regras, conflitos são solucionados e, ainda, uma proteção se faz na fantasia. Vejo o brincar como mediador da criação de sentidos, porém, aqui, o adulto "não está pra brincadeira", dirigindo-a, infantilizando-a e deformando a criação de sentidos.

Um terceiro extrato do diário de campo reflete a forma como essas crianças utilizam o brincar diante da doença/morte. Respeitar regras e, quem sabe, ganhar na "jogada seguinte"; poder expressar-se com liberdade e espontaneidade, registrando em cores e formas sentimentos, na maioria das vezes, difícil de colocar em palavras, é algo disponível no papel em branco. As histórias infantis permitem uma identificação com os personagens, abrindo a possibilidade de compreensão do vivido.

Estou lendo uma história para Ricardo; ele ainda não sabe ler, nem sua mãe. Ele ouve atentamente; parece não mexer um músculo sequer; às vezes, seus olhinhos piscam e a boca se abre em espanto. Termino uma, outra e mais outra... "Pode ser qualquer livro, tia!" 
Pego um com figuras e mostro-lhe que este não tem letras, e os outros, já os lemos. Então Ricardo começa a ler as figuras e inventamos uma história que todos ouvem curiosos; toda a enfermaria se envolve no destino dos "nossos" personagens: bichos, mãe, travessuras, presentes, morte, acidente, etc. Faz-se uma miscelânea com humor trágico (extrato do diário de campo).

O encontro com a morte promove um tipo de aprendizagem singular. Assistir alguém morrer é ser tomado de uma tensão e cumplicidade desestruturante do que acreditamos ser. Compreender a finitude remete ao imediatismo do viver projetos aquie-agora; desejos são revestidos de uma importância essencial; a sensibilidade guia pequenas escolhas cotidianas; a existência é impregnada de sentido. Esse conteúdo é aprendido, parece-me, quando uma junção de informações se faz na percepção, em especial da criança - os profissionais sabem, os familiares também, então a criança intui esse saber velado - que coloca em uso de imediato e o compartilha com seu grupo (daqueles que se encontram com a morte). Essa dimensão é promotora da criação de sentidos e elo que poderá diferenciar entre vida e morte - o que aprende aqui pode vir a morrer com dignidade ou ter esse aprender como sustentação para o enfrentamento da doença, permitindo sua (sobre)vivência.

Estamos brincando de construção. Victória monta uma ponte; João e Ricardo montam pistas para carrinhos; José monta uma casa numa base de encaixe. Por um tempo, estamos todos absorvidos em nossas construções. José inicia a montagem de um prédio, empilhando blocos; estes caem com frequência; eu o ajudo. De repente, o cair dos blocos vira brincadeira. Ele pergunta: "Quem derrubou o meu prédio?" E ele mesmo responde: “Foi eu!" Em seguida, Victória larga sua construção para derrubar o prédio de José, assumindo "Foi eu!" Na fantasia, construímos e destruímos muitos prédios, assumindo a responsabilidade pelas destruições. "Foi eu!" Respondíamos e gargalhávamos (extrato do diário de campo).

Construir, destruir e assumir responsabilidade pelas construções/destruições (extrato acima) é o que o encontro com a morte ensina. Somos os únicos responsáveis por nossa construção, isto é, pelos projetos que escolhemos responsavelmente em nossa existência.

O educativo se apresenta na atividade de criar sentidos, é construído nos entre-pólos, e essa população que enfrenta a doença/morte busca mediadores para o seu aprender. Os pólos movimentam-se em espiral e encontram-se entrelaçados por interseções onde a tensão entre-pólos se faz presente. Esse processo insere-se numa dimensão educativa, isto é, a Criação de Sentidos se realiza educando e sendo educado (todos aprendem e ensinam), mediado pelos itens acima discutidos (atitudes, com-vivência, brincar, encontro com a morte). Todo esse processo se funde em um contexto maior que denominei sociohistórico, no qual as crenças vigentes, socialmente construídas, compõem o fundo da atividade de Criação de Sentidos.

O núcleo apresenta a criação de sentidos. O sentido é a abertura da compreensão (Heidegger 2000). O sentido é a abertura à fluidez de vivências no agora/presente (Rogers, 1982). Nesse contexto de criação, sentidos surgem numa velocidade e complexidade inerentes a esse processo. Tal característica dificulta a apreensão do processo como totalidade. A figura abaixo sintetiza os conceitos discutidos até aqui; busca, também, dar uma idéia da diversidade do processo de Criação de Sentidos realizado junto à doença e à percepção da morte de si e do outro.
O encontro com a morte promove um tipo de aprendizagem singular. Assistir alguém morrer é ser tomado de uma tensão e cumplicidade desestruturante do que acreditamos ser. Compreender a finitude remete ao imediatismo do viver projetos aquie-agora; desejos são revestidos de uma importância essencial; a sensibilidade guia pequenas escolhas cotidianas; a existência é impregnada de sentido. 


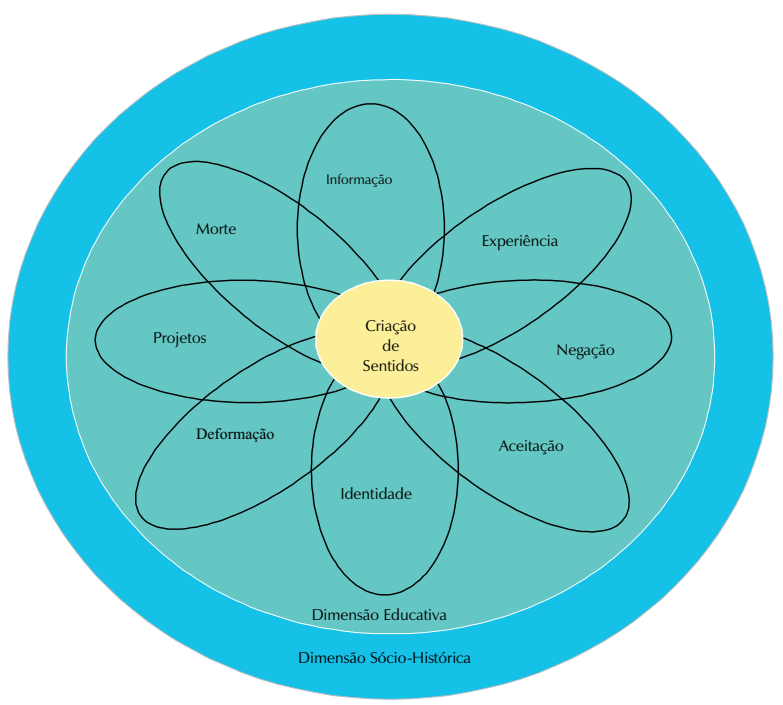

Figura 1: As diversas nuances da rede de aprendizagem "denominada" Criação de Sentidos.

Alguns sentidos que destaco são: a valorização da vida/existência, a transcendência que se faz na presença do sagrado nos rituais cotidianos, a percepção do ser como inacabado, a gratuidade e beleza da vida/ existência, a autenticidade no sentir para conhecer, o cuidado com o humano na partilha de um "destino" comum, a aprendizagem como instrumento de vida, a educação como resposta à morte.

Penso que a contribuição deste estudo acerca da aprendizagem hospitalar é possibilitar uma reflexão aos educadores que se encontram nesse contexto (enfermeiros, assistentes sociais, médicos, psicólogos, nutricionistas, pais, voluntários, funcionários administrativos), alertando para a importância central da consciência do jeito de ser criança que se encontra nessa rede de aprendizado peculiar.

Nesta pesquisa, destaquei a convivência/ vivência como possibilidade de conhecer. Como um conhecimento é produzido a partir da vivência? A convivência nos coloca diante dos paradoxos, em especial, os paradoxos teóricos. Perceber-se "incapaz de pensar inteiro" (sem dualismos cartesianos) e intuir que há um lugar onde essa possibilidade se faz, isto é, na vivência, transforma-se num ponto fundamental dessa produção, assim como envolver-se afetivamente e distanciarse reflexivamente e, nesse movimento, enunciar o conhecimento.

Como captar e registrar um processo? Diria que imagino esse processo como algo borbulhante, fervente, uma "lava de vulcão" ou um "caldeirão de bruxa", e que, vivendoo, senti-me em contato com esses ingredientes e, tantas vezes, como o próprio ingrediente dessas "receitas vivas".

Sendo pesquisadora/educadora, olhares profundos me indagaram, silêncios se elevaram diante de mim, vozes gritaram no meu ouvido e eu não soube responder. Foi buscando em mim que aprendi que estava no pólo da informação, e, então, pude sentir/experienciar e aprender que tinha, como resposta, a minha pre-sença: deixei-me olhar profundamente, silenciei de mãos dadas e agi junto aos gritos.

Minha convivência junto às crianças-comcâncer levou-me a compreender a aprendizagem como instrumento de vida. Como seres humanos, estamos, em nossa existência, imersos no aprender como abertura 
para tudo o que a essa existência se apresenta. Nesse tempo dedicado junto às crianças, posso dizer que, no cotidiano, estive próxima, em palavras e gestos. Quanto às palavras ditas, não constituem a língua desse lugar, mas os gestos são uma linguagem "completa", preciosa, e são acolhidos como sagrados: abracei, sorri, toquei, mostrei meus olhos úmidos de lágrimas, limpei saliva que escorria, arranquei fios do meu cabelo para trocar com quem estava ficando careca, peguei no colo, segurei a mão em incontáveis ocasiões, caminhei ao lado pelo "corredor escuro", ofereci meu braço, ao ser solicitado, para que nele ligassem os fios e pudesse descansar aqueles pequeninos braços "tão cheios de fios".

Não se trata de falar de morte, mesmo porque "falatório" não é aceito nesse lugar. Como educador, é necessário responder à morte, e, nessa resposta, educar. Penso que a aprendizagem se realiza nesses encontros promotores de Criação de Sentidos e que ela se dá com todos os que estão nesse contexto.

Aquele que se propõe mediar processos diante do adoecer-morrer necessita compreender o lugar que ocupa: o de instrumento pedagógico colocado em alto grau de disponibilidade. Penso que o educador humano é aquele que assume, com coragem, sua própria construção junto àqueles com quem participa do aprender. Como educadora aprendiz, apresentei, aqui, meu percurso de aprendizagem nesse tempo, para, quem sabe, iluminar outros educadores que escolham "visitar essa cidade chamada doença-hospitalmorte".

Maria do Rosário Camacho Psicóloga e Mestre em Educação pela Universidade Federal do Espírito Santo (UFES). Rua das Amoras, $n^{\circ} 6$ - Ilha dos Bentos 29104-320 Vila Velha - ES E-mail:mrosarioc@ig.com.br

AMATUZZI, M. O Resgate da Fala Autêntica. Campinas: Papirus, 1989.

Por uma Psicologia Humana. Campinas: Alínea, 2001.

ARIÉS, P. História Social da Criança e da Família. Rio de Janeiro: Ed. Guanabara, 1981.

BENJAMIN, Walter. Obras Escolhidas, v. 1. Trad. Sérgio Paulo Rouanet. São Paulo: Brasiliense, 1985

Reflexões sobre a Criança, o Brinquedo e a Educação. São Paulo: Ed. 34, 2002.

FOUCAULT, M. Vigiar e Punir. Petrópolis: Vozes, 1977.

FORGUIERI, I. C. Psicologia Fenomenológica: Fundamentos, Métodos e Pesquisa. São Paulo: Pioneira, 1993.

HEIDEGGER, M. Ser e Tempo - parte I. 10ª ed. Petrópolis: Vozes, 2001.

Ser e Tempo - parte II. 7ª̣ ed.Petrópolis: Vozes, 2000.
ROGERS, C. R. Tornar-se Pessoa. São Paulo: Martins Fontes, 1982.

Referências 